\title{
A trajetória da assistência estudantil na educação superior brasileira
}

The trajectory of student assistance in Brazilian higher education

\author{
Thaís Kristosch Imperatori \\ Assistente social da Universidade de Brasília-UnB, mestre em \\ Política Social e doutoranda em Política Social pela UnB, Brasil. \\ thaisimperatori@yahoo.com.br
}

Resumo: O objetivo do presente artigo é problematizar a trajetória histórica dessa política no Brasil até a implementação do PNAES. A partir de pesquisa bibliográfica, será analisada a definição de assistência estudantil, situada entre a assistência social e a educação. Também será analisado seu reconhecimento enquanto direito social e política pública. Espera-se contribuir para a discussão, tendo em vista a escassez de estudos nessa temática.

Palavras-chave: Assistência estudantil. Educação superior. Assistência social. PNAES.

\begin{abstract}
This article introduces the main results of the theoretical production study about student assistance; therefore, it characterizes itself as a state-of-the-art research. We understand that student assistance — as a public policy — is a process in construction, which requires continuity, perfectioning and qualification, so as to answer to the diversity of the student issues and to contribute effectively for higher education to be, indeed, everyone's right.
\end{abstract}

Keywords: Higher education. Student assistance. Social right.

\section{Introdução}

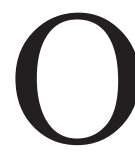

direito à educação é garantido desde a Constituição Imperial de 1824, passando por processos de avanços e retrocessos. Cury (2007), ao traçar o percurso histórico da política de educação, observa que em determinados momentos a educação foi garantida como direito, como na Constituição de 1824, enquanto em outros, como na Constituição Republicana de 1891, foi retirada do Estado a obrigação de oferecer educação primária.

Da mesma forma que o direito à educação não é recente, as ações de assistência ao estudante remetem aos anos 1930, com os programas de alimenta- 
ção e moradia universitária. A primeira manifestação com o intuito de apoiar os estudantes universitários ocorreu em 1928, com a inauguração da Casa do Estudante Brasileiro, localizada em Paris, e destinada a auxiliar estudantes que estudavam na capital francesa e tinham dificuldades em se manter na cidade (Costa, 2010).

O governo Getúlio Vargas foi um marco nas políticas sociais e passou a reconhecer a educação como um direito público regulamentado pelo Estado (Vasconcelos, 2010). Em 1931, através da Reforma Francisco Campos, que instituiu a Lei Orgânica do Ensino Superior pelo Decreto n. 19.851/1931, são propostas medidas de providência e beneficência aos corpos discentes dos institutos universitários, incluídas bolsas de estudos para amparar os estudantes reconhecidamente pobres.

Essa lei foi incorporada na Constituição de 1934, que assegurou a assistência aos estudantes, sendo declarado no art. 157 que "parte dos mesmos fundos se aplicará em auxílio a alunos necessitados, mediante fornecimento gratuito de material escolar, bolsas de estudos, assistência alimentar, dentária e para vilegiaturas". A assistência aos estudantes foi extensiva para todos os níveis de ensino nos anos 1940, estando presente na Constituição de 1946, art. 172, segundo o qual "cada sistema de ensino terá, obrigatoriamente, serviços de assistência educacional que assegurem aos alunos necessitados, condições de eficiência escolar”.

Destaca-se que a Lei de Diretrizes e Bases da Educação Nacional (LDB), de 1961, apresenta um título específico para abordar a Assistência Social Escolar, tratando-a como um direito discente nos artigos 90 e 91 :

Art. 90 Em cooperação com outros órgãos ou não, incumbe aos sistemas de ensino, técnica e administrativamente, prover, bem como orientar, fiscalizar e estimular os serviços de assistência social, médico-odontológico e de enfermagem aos alunos.

Art. 91 A assistência social escolar será prestada nas escolas, sob a orientação dos respectivos diretores, através de serviços que atendam ao tratamento dos casos individuais, à aplicação de técnicas de grupo e à organização social da comunidade. 
A expansão da educação superior iniciou-se entre as décadas de 1950 e 1970. Na análise de Vasconcelos (2010, p. 401), “entre as décadas de 50 e 70 criaram-se universidades federais em todo o Brasil, ao menos uma em cada estado, além de universidades estaduais, municipais e particulares". Mas foi na década de 1970 que o ensino superior se expandiu, resultando na ampliação do número de matrículas de 300 mil, em 1970, para um milhão e meio, em 1980.

Tendo em vista a expansão das vagas, a juventude das classes mais baixas passou a ter maior acesso à universidade, o que gerou demandas por ações específicas para atendimento desse público. Muitos desses jovens saíam de suas cidades para as capitais buscando formação acadêmica. Começaram reivindicações e lutas, juntamente com o movimento estudantil, que levaram as instituições de educação a assumirem a responsabilidade pela manutenção de algumas necessidades básicas dos estudantes que não tinham recursos (Sousa, 2005).

A Constituição de 1967 manteve os mesmos pressupostos referentes à assistência estudantil que a anterior, acrescentado apenas o direito à igualdade de oportunidades educativas (Costa, 2010). Destaca-se, no artigo 176, a garantia do ensino médio gratuito e no ensino superior para aqueles que, "demonstrando efetivo aproveitamento, provarem falta ou insuficiência de recursos".

Ainda na década de 1970, foi criado o Departamento de Assistência ao Estudante (DAE), vinculado ao Ministério da Educação e Cultura, que implantou programas de assistência aos estudantes, como Bolsas de Trabalho, através das quais eram proporcionadas oportunidades de exercício profissional em órgãos ou entidades públicas ou particulares; e Bolsas de Estudo, por meio das quais o estudante recebia uma verba para sua manutenção, sem a realização de atividades em contrapartida. Também eram prioritários programas de alimentação, moradia e assistência médico-odontológica. Destaca-se que tais ações estiveram respaldas na LDB de 1971, segundo a qual cada sistema de ensino compreenderá obrigatoriamente serviços de assistência educacional. Tais serviços são especificados no artigo 62:

Art. $62[\ldots]$

$\S 1^{\circ}$ Os serviços de assistência educacional de que trata êste artigo destinar-se-ão, de preferência, a garantir o cumprimento da obrigatoriedade escolar e incluirão 
auxílios para a aquisição de material escolar, transporte, vestuário, alimentação, tratamento médico e dentário e outras formas de assistência familiar.

$\S 2^{\circ} \mathrm{O}$ Poder Público estimulará a organização de entidades locais de assistência educacional, constituídas de pessoas de comprovada idoneidade, devotadas aos problemas sócio-educacionais que, em colaboração com a comunidade, possam incluir-se da execução total ou parcial dos serviços de que trata este artigo, assim como da adjudicação de bolsas de estudo.

Ainda em 1972, foi instituído o programa assistencial "Bolsa Trabalho", pelo Decreto n. 69.927, destinado a discentes de baixa condição financeira, de todos os níveis de ensino, que desenvolvessem atividades profissionais. $\mathrm{O}$ objetivo era "associar auxílio financeiro e educação" (Ramalho, 2013, p. 28) e buscava contribuir para o preparo dos alunos para o mercado de trabalho.

No fim dos anos 1980, o DAE foi extinto, e as ações de assistência ao estudante ficaram fragmentadas em cada instituição de ensino. A assistência passou a ser composta por ações escassas e pulverizadas. Além disso, da mesma forma que a assistência social, a assistência estudantil foi marcada por relações clientelistas, que impediam a sua consolidação. Barbosa (2009) observa que historicamente as atividades de assistência estudantil têm sido desenvolvidas pelas instituições a partir das demandas dos estudantes.

A assistência desenvolvida na universidade, do ponto de vista de sua implementação técnica, expressa, por um lado, o descaso com a área social e revela-se, por outro, enquanto um campo onde prevalecem concepções paternalistas e clientelistas, traduzidas em práticas de ajuda e no uso indevido dos recursos públicos disponíveis (Barbosa, 2009, p. 38).

A Constituição Federal de 1988, também chamada Constituição Cidadã, foi resultado da pressão de diversos movimentos sociais e consolidou direitos sociais e políticos reivindicados no processo de redemocratização. Nessa Carta Magna, a educação, ao lado de outras políticas sociais, é reconhecida como direito social:

Art. 205. A educação, direito de todos e dever do Estado e da família, será provida e incentivada com a colaboração da sociedade, visando ao pleno desenvolvi- 
mento da pessoa, seu preparo para o exercício da cidadania e sua qualificação para o trabalho.

A regulamentação da política de educação ocorreu pela Lei n. 9.394/1996, Lei de Diretrizes e Bases da Educação Nacional, que estabeleceu as diretrizes para os diferentes níveis de educação e também explicitou aspectos relacionados à assistência dos discentes na educação.

Art. $4^{\circ} \mathrm{O}$ dever do Estado com educação escolar pública será efetivado mediante a garantia de:

$[\ldots]$

VIII - atendimento ao educando, em todas as etapas da educação básica, por meio de programas suplementares de material didático-escolar, transporte, alimentação e assistência à saúde.

No que se refere à educação superior, a legislação autoriza que ela seja ministrada por instituições de ensino superior, públicas ou privadas, condicionadas ao reconhecimento de cursos, credenciamento das instituições e processo periódico e regular de avaliação. A assistência estudantil na educação superior foi regulamentada anos mais tarde.

\section{As condições de permanência na educação superior e assistência estudantil}

Considerando o foco do artigo, questiona-se em que medida as ações de assistência estudantil podem possibilitar maior ampliação do acesso, permanência e diplomação na educação superior. Segundo Bardagi e Hutz (2009), a literatura apresenta variadas causas para a evasão na educação superior, como descontentamento com horários das disciplinas, falta de cursos noturnos, impossibilidade de conciliar trabalho e estudo, mau relacionamento professor-aluno, pouca integração social à universidade, expectativas não correspondidas e falta de informações sobre curso e profissão, mau desempenho acadêmico e reprovações, problemas financeiros. 
Ao lado desses fatores, a questão socioeconômica tem impacto direto na continuidade dos estudos. Nesse sentido, é fundamental pensar em estratégias para uma efetiva democratização da educação, que inclua ampliação do acesso e fortalecimento do ensino público, além de políticas que possibilitem a permanência dos estudantes no sistema educacional (Vasconcelos, 2010). Isso porque, nos termos de Felicetti e Morosini (2009, p. 11), "questões como sexo, raça, condições socioeconômicas, idade ou deficiências não podem ser fatores que venham a se tornar obstáculos para o acesso, para a participação, ou para os resultados obtidos no Ensino Superior".

Na visão de Vargas (2008), as desigualdades de acesso aos capitais econômico, social e cultural geram necessidades específicas para os estudantes e influenciam as possibilidades de conclusão dos estudos. Nesse sentido,

dificuldades de cunho econômico podem interferir na trajetória acadêmica de estudantes de baixa renda, seja através da falta de recursos necessários para o acesso a importantes bens e práticas culturais, seja pela necessidade de conciliar estudos e trabalho (Vargas, 2008, p. 50).

Na mesma direção, Finatti et al. (2007, p. 248) afirmam que, "para que o aluno possa desenvolver-se em sua plenitude acadêmica, é necessário associar, à qualidade do ensino ministrado, uma política efetiva de assistência, em termos de moradia, alimentação, saúde, esporte, cultura e lazer, entre outras condições". Vasconcelos (2010) também compreende que a assistência estudantil possibilita os recursos para a superação dos obstáculos para o bom desempenho acadêmico, $\mathrm{o}$ que permite que o estudante desenvolva sua graduação e obtenha um bom desempenho curricular, minimizando situações de abandono e trancamento de matrícula.

Nesse contexto, ganha relevância a política de assistência estudantil, compreendida por Barbosa $(2009$, p. 39) como

o conjunto de políticas realizadas através dos programas de Promoção, Assistência e Apoio, que têm como objetivo principal criar condições que contribuam para a permanência dos estudantes nos estabelecimentos de ensino superior, melhorando sua qualidade de vida e consequentemente seu desempenho acadêmico e de cidadãos. 
Amaral e Nascimento (2010, p. 3) reafirmam a importância da assistência estudantil ao dizer que

Entende-se que os programas e projetos de assistência estudantil devam ser desenvolvidos como instrumentos de acesso, permanência e conclusão de curso dos estudantes nas instituições públicas, tendo como pressuposto que a Assistência Estudantil é uma política essencial no contexto do ensino, da pesquisa e da extensão.

Destaca-se que a assistência estudantil tem grande relevância no contexto brasileiro devido às suas altas taxas de desigualdade social, que se expressam na permanência dos estudantes nos seus cursos de graduação (Araújo, 2003). Pesquisa publicada pela Andifes (2011) mapeou o perfil socioeconômico e cultural dos estudantes de graduação das universidades federais brasileiras em 2010 e identificou que $41 \%$ das famílias dos estudantes recebem até três salários mínimos. Essa distribuição ocorre de forma desigual nas regiões brasileiras. No Nordeste e no Norte, esse percentual é de 50\% e 63\%, respectivamente, enquanto nas regiões Sudeste, Sul e Centro-Oeste é de aproximadamente 30\%.

Além disso, a pesquisa apresentou dados relevantes sobre fatores que possibilitam a permanência na universidade, como transporte e moradia. Em relação ao transporte, $56,6 \%$ dos estudantes responderam utilizar transporte coletivo, em 2010, enquanto em 1996/1997, esse meio de transporte era usado por $60,6 \%$ dos estudantes. Sobre as condições de moradia, 2,5\% dos estudantes moram em residências universitárias, com destaque para a região Norte, com o menor percentual de estudantes nessa condição equivalente a $0,63 \%$, e no Sul, onde o percentual é maior, $3,46 \%$.

Destaca-se ainda que a relevância da assistência estudantil está expressa no Plano Nacional de Educação (Brasil, 2001), que estabelece como um dos objetivos e metas da educação superior, "estimular a adoção, pelas instituições públicas, de programas de assistência estudantil, tais como bolsa-trabalho ou outros destinados a apoiar os estudantes carentes que demonstrarem bom desempenho acadêmico".

Na leitura de Araújo (2003), a assistência ao estudante é permeada por ambiguidades e contradições, ora entendida como investimento, ora como 
direito de cidadania. Por outro lado, é caracterizada pela seletividade dos carentes e na capacidade individual do estudante. Na mesma direção, Barbosa (2009) observa a tensão entre os critérios de necessidade e aqueles baseados em aspectos meritocráticos, resultantes da escassez de recursos na área.

Angelim $(2010$, p. 2) também analisa a política de assistência estudantil e de que forma ela vem sendo implementada nas instituições, ao afirmar que:

De modo geral, a política de assistência estudantil junto aos estudantes de universidades públicas tem se caracterizado na contemporaneidade por sua natureza focalizada; pela inexistência de mecanismos de controle social sobre a mesma; pela terceirização dos serviços; pela concessão de bolsas financeiras para apoio à moradia, alimentação, transporte em detrimento da oferta de serviços como restaurante universitário, residência estudantil, entre outros.

Ressalta-se ainda que todo o processo de construção da assistência estudantil do Brasil foi marcado por lutas e disputas políticas.

Ao longo de toda a criação e desenvolvimento político, econômico e social das universidades no Brasil, através de alguns segmentos sociais, da base estudantil, os docentes e representantes do sistema educacional travaram várias lutas e embates para a conquista da educação com qualidade e melhoria do ensino público. Uma delas foi assegurar a assistência estudantil, significando um avanço no acesso à universidade (Barbosa, 2009, p. 62).

De acordo com Vasconcelos (2010), a trajetória da assistência estudantil está conectada com a trajetória da assistência social, sendo as duas resultantes de lutas de movimentos sociais no contexto do fim da ditadura militar e promulgação da Constituição Federal de 1988. Nesse contexto, a autora destaca que surgiram duas grandes frentes de discussão política sobre as questões relativas à assistência social: o Fórum Nacional de Pró-reitores de Assuntos Comunitários e Estudantis (Fonaprace) ${ }^{1}$ e a Associação Nacional dos Dirigentes das Instituições

1. O Fonaprace foi criado em 1987 e congrega os Pró-reitores, Sub-reitores, Decanos, Coordenadores ou responsáveis pelos assuntos comunitários e estudantis das IFES. Informações complementares podem ser obtidas em http://www.fonaprace.andifes.org.br. 
Federais de Ensino Superior (Andifes), que defendiam a integração regional e nacional das instituições de ensino superior, visando garantir igualdade de oportunidades para os estudantes das Instituições Federais de Ensino Superior (Ifes) na perspectiva do direito social. Isso inclui a permanência e conclusão do curso e a prevenção da retenção e evasão escolar por motivos socioeconômicos.

Para Araújo e Bezerra (2007), além do Fonaprace e da Andifes, outras entidades engajadas na luta pela efetivação da assistência estudantil são a União Nacional dos Estudantes (UNE) e a Secretaria Nacional de Casa de Estudantes (Sence). Por outro lado, segundo Costa (2010), as principais associações do setor privado, como a Associação Brasileira de Mantenedoras de Ensino Superior (ABMES), o Sindicato Nacional dos Docentes das Instituições de Ensino Superior (Andes) e o Conselho de Reitores das Universidades Brasileiras (Crub), não demonstram preocupação em elaborar políticas e projetos nessa área.

Percebe-se, então, que apesar de se reconhecer os aspectos socioeconômicos como um importante elemento que possibilita a permanência de estudantes nas instituições de educação superior, a assistência estudantil é um campo de disputas a ser consolidado enquanto uma política pública. É nesse cenário que se contextualiza o Programa Nacional de Assistência Estudantil (PNAES), com foco no impacto dos fatores socioeconômicos na permanência dos estudantes no ensino superior.

\section{0 Programa Nacional de Assistência Estudantil — PNAES}

Ações na área de assistência estudantil não são recentes, como visto na seção anterior. Porém, percebe-se uma escassez de pesquisas sobre essa temática. (Vargas, 2008; Menezes, 2003; Garrido; Mercuri, 2013) A literatura apresenta, em sua maioria, estudos de casos e não pesquisas nacionais ou regionais, o que torna a leitura sobre a realidade da assistência estudantil fragmentada. ${ }^{2}$

2. Há estudos como o do Centro Federal de Educação Tecnológica de Minas Gerais (Ramalho, 2013); Universidade Federal do Vale do São Francisco (Angelim, 2010); da Universidade de Brasília, tratando da situação de saúde mental de estudantes residentes na moradia estudantil (Osse; Costa, 2011); da Universidade Federal de Minas Gerais, relacionando questões socioeconômicas e culturais dos estudantes com evasão 
O PNAES foi instituído em âmbito federal pela Portaria Normativa 39, de 12 de dezembro de 2007, para os estudantes de cursos de graduação presenciais das Ifes, sendo implementado a partir do ano de 2008. Trata-se de um marco histórico para a política de assistência por definir suas áreas de ação e ser o referencial para os programas e projetos realizados nas diversas Ifes do Brasil. $\mathrm{Na}$ análise de Vasconcelos (2010, p. 405).

Essa conquista foi fruto de esforços coletivas de dirigentes, docentes e discentes e representou a consolidação de uma luta histórica em torno da garantia da assistência estudantil enquanto um direito social voltado para igualdade de oportunidades aos estudantes do ensino superior público.

A partir do PNAES, a assistência estudantil se efetiva em articulação com atividades de ensino, pesquisa e extensão, com foco principal na permanência desses estudantes nos seus cursos de graduação. Além disso,

Art. $2^{\circ}[\ldots]$

Parágrafo único. Compreendem-se como ações de assistência estudantil iniciativas desenvolvidas nas seguintes áreas:

I - moradia estudantil;

II - alimentação;

III - transporte;

IV — assistência à saúde;

$\mathrm{V}$ — inclusão digital;

VI - cultura;

VII - esporte;

VIII - creche; e

IX - apoio pedagógico.

(Adachi, 2009) e tratando da assistência estudantil e ingresso no mercado de trabalho (Vargas 2008); da Universidade Federal de Alagoas, com foco no Programa Residência Universitária (Araújo, 2003); da Universidade Federal da Paraíba, especificamente a assistência na residência universitária (Barbosa, 2009); da Universidade Federal do Rio Grande do Sul e da Pontifícia Universidade Católica do Rio Grande do Sul, em um estudo comparativo (Costa, 2010); do Instituto Federal do Maranhão (Amaral; Nascimento, 2010); da Universidade Estadual de Londrina (Finatti; Alves; Silveira, 2007); e da Universidade Federal do Goiás, com foco na assistência de saúde mental aos discentes oferecido pela instituição (Ramos, 2012). 
A assistência estudantil é composta por uma variedade de eixos de atuação. Percebe-se, então, que a proposta do PNAES é articular diferentes áreas e, consequentemente, diferentes políticas sociais, visando garantir um padrão de proteção social amplo. É interessante observar que são definidas as ações e não as formas de se executar as ações, o que resulta na diversidade de projetos e serviços implementados em cada Ifes.

Em relação à moradia estudantil, por exemplo, em algumas instituições existem residências universitárias, onde é disponibilizada toda a infraestrutura, tal como quartos mobiliados e com eletrodomésticos, enquanto em outras é fornecida uma bolsa destinada ao pagamento dos gastos com moradia com valores variados. $\mathrm{O}$ mesmo ocorre com alimentação. Em algumas Ifes são priorizados os restaurantes universitários, com subvenções aos estudantes e, em outras, é fornecido o recurso monetário para utilização em lanchonetes ou restaurantes. Há ainda casos em que são fornecidos tanto serviços como benefícios monetários. Outro aspecto interessante é a possibilidade de acumulação dos programas de assistência estudantil, o que permite que o estudante participe, por exemplo, de ações de moradia, alimentação e transporte simultaneamente.

Na compreensão de Finatti et al. (2007), a assistência estudantil perpassa todas as áreas dos direitos humanos, uma vez que compreende ações que envolvem ideais condições de saúde, acesso aos instrumentais pedagógicos para formação profissional, acompanhamento das necessidades educativas especiais, além de necessidades básicas dos estudantes, tais como moradia, alimentação, transporte e recursos financeiros.

O público-alvo da assistência estudantil é descrito no artigo $4^{\circ}$ da Portaria Normativa:

Art. $4^{\circ}$ As ações do PNAES atenderão a estudantes matriculados em cursos presenciais de graduação, prioritariamente, selecionados por critérios sócio-econômicos, sem prejuízo de demais requisitos fixados pelas instituições de educação superior em ato próprio.

Em outras palavras, entende-se que quaisquer estudantes poderão ser atendidos por ações de assistência estudantil, sendo prioritários os vulneráveis em termos socioeconômicos, podendo ser estabelecidos outros requisitos pelas 
instituições. É uma política que, por não ter critérios restritivos explícitos, tem caráter fortemente amplo, o que será alterado pela regulamentação mais recente do PNAES. Ressalta-se ainda não se tratar de um benefício contributivo, o que o aproxima do caráter da política de assistência social. ${ }^{3}$

Essa Portaria foi alterada em 2010, e o PNAES passou a ser regulamentada pelo Decreto $\mathrm{n}^{\circ}$ 7.234, de 19 de julho de 2010, um instrumento jurídico com mais força e que permite maior estabilidade ao programa. Várias foram as inovações dessa nova regulamentação. A primeira é a definição da finalidade da PNAES como "ampliar as condições de permanência dos jovens na educação superior pública federal.", com os seguintes objetivos:

\section{Art. $2^{\circ}$ São objetivos do PNAES:}

I - democratizar as condições de permanência dos jovens na educação superior pública federal;

II - minimizar os efeitos das desigualdades sociais e regionais na permanência e conclusão da educação superior;

III - reduzir as taxas de retenção e evasão; e

IV - contribuir para a promoção da inclusão social pela educação.

Há a busca, então, de definição para o programa, a partir do estabelecimento da finalidade e dos objetivos, o que possibilita ter uma referência comum a todas as Ifes brasileiras. Em relação às áreas de ação da assistência estudantil, inclui-se outra além das estabelecidas na Portaria anterior, que trata do " $\mathrm{X}$ acesso, participação e aprendizagem de estudantes com deficiência, transtornos globais do desenvolvimento e altas habilidades e superdotação". Considera-se, então, que além de aspectos socioeconômicos, a população com deficiência também demanda ações específicas no ensino superior.

Entretanto, a principal alteração apresentada por esse Decreto trata do público-alvo das ações. Visualiza-se uma restrição do acesso a essa política por meio da sua focalização, sendo estabelecido que:

3. De acordo com a Lei Orgânica da Assistência Social, "Art. $1^{\circ}$ A assistência social, direito do cidadão e dever do Estado, é Política de Seguridade Social não contributiva, que provê os mínimos sociais, realizada através de um conjunto integrado de ações de iniciativa pública e da sociedade, para garantir o atendimento às necessidades básicas”. (grifos meus) 
Art. $5^{\circ}$ Serão atendidos no âmbito do PNAES prioritariamente estudantes oriundos da rede pública de educação básica ou com renda familiar per capita de até um salário mínimo e meio, sem prejuízo de demais requisitos fixados pelas instituições federais de ensino superior.

Dessa forma, o acesso à assistência estudantil foi fixado a partir de um critério de renda, mais restritivo que o anterior, que ainda poderá ser acrescido de outros critérios nas instituições. Isso significa que não se trata de uma política universal para todos os estudantes de graduação. Ao contrário, há uma restrição significativa dos beneficiários. Outro aspecto interessante é observar que o usuário da assistência estudantil é o próprio estudante e não sua família, o que agrega um caráter individual ao programa.

Há ainda uma lacuna tanto nessa legislação como na anterior, sobre como será realizada a verificação desses critérios socioeconômicos, o que dá margem para o uso clientelista do programa, inclusive se pensarmos que não é apenas a renda que implica vulnerabilidade social. Além disso, não são apresentados critérios para permanência dos estudantes no PNAES e nem a articulação do acesso com a finalidade do programa, expresso por meio do rendimento acadêmico.

Apesar de o PNAES ser um programa no âmbito federal, sua execução é descentralizada. Cada universidade tem autonomia de gestão para utilizar os recursos disponibilizados, conforme as suas necessidades e especificidades locais, o que permite maior eficiência. Isso está de acordo com a Constituição Federal de 1988 que, no seu art. 207, estabelece que "As universidades gozam de autonomia didático-científica, administrativa e de gestão financeira e patrimonial, e obedecerão ao princípio de indissociabilidade entre ensino, pesquisa e extensão". Infere-se que o programa será desenvolvido no âmbito das próprias IFES, não havendo restrições legais sobre a terceirização das ações de assistência estudantil ou parcerias com outras instituições ou organizações não governamentais.

\section{Considerações finais}

Considerando essas breves reflexões sobre o PNAES, percebe-se a complexidade desse programa e suas contradições. Trata-se de uma política que se 
situa na interseção da assistência social com a educação e representa um avanço no reconhecimento da assistência estudantil como um direito social. Por isso, é importante considerar o pressuposto da assistência estudantil de que fatores socioeconômicos interferem na trajetória dos estudantes nos seus cursos de graduação, gerando inclusive abandono escolar. Isso é um avanço ao se compreender que o desempenho acadêmico não é resultado do binômio capacidade-oportunidade, mas que inclui outros elementos, tais como a situação socioeconômica expressa por moradia, alimentação, transporte, entre outros.

Além disso, a assistência estudantil avança em relação a alguns elementos da assistência social. Historicamente, a assistência social foi construída em oposição ao trabalho, sendo destinada aos incapazes para o trabalho, como idosos e pessoas com deficiência. Aos considerados capazes, era imposta a responsabilidade de trabalhar. Isso gera, nos termos de Boschetti (2003, p. 47), "uma contraditória relação de tensão e atração" entre assistência e trabalho, principalmente no século XX, quando até aqueles capazes de trabalhar, devido ao desemprego em massa, recorrem à assistência social.

A assistência estudantil, enquanto desmembramento da assistência social no contexto da educação, considera os estudantes em um processo de formação para o trabalho. De acordo com a Constituição Federal de 1988, art. 205, uma das finalidades da educação é a "qualificação para o trabalho". Se for considerada a educação superior, esse princípio é ainda mais forte, tendo em vista a formação especializada dos cursos. Nesse sentido, seria legítimo que os estudantes desfrutassem de assistência enquanto estivessem no seu processo de formação acadêmica.

O levantamento da literatura mostra que não se trata de uma política consolidada, mas que se situa em um campo de disputa e que está passando por um processo de legitimação, principalmente após sua regulamentação pela Portaria Normativa n. 39/2007 e pelo Decreto n. 7.234/2010. Nesse marco legal, a assistência estudantil é reconhecida como estratégia de combate às desigualdades sociais, ampliação e democratização das condições de acesso e permanência no ensino superior público federal, com uma definição bastante ampliada.

Há muitos desafios a serem superados ainda. Primeiramente, é perceber que a assistência estudantil só é reconhecida, no contexto do PNAES, para as 
Ifes, estando de fora as demais instituições que oferecem educação superior. Além disso, é importante refletir sobre a própria definição do público-alvo, especificado a partir de um critério de renda. Cabe questionar em que medida somente a renda expressa vulnerabilidades sociais e se esse valor de renda se aplica a todas as realidades do Brasil.

Outro desafio trata da escassez de dados sobre as ações de assistência estudantil. Existem apenas informações pulverizadas, divulgadas pelas próprias instituições ou em estudos de caso, sendo necessário criar bancos de dados específicos para esse programa. Relacionado a isso, é necessário ampliar os dados sobre a eficácia do PNAES, para conhecer o desempenho acadêmico dos estudantes participantes, uma vez que o programa visa permitir a permanência e diplomação desses alunos.

\section{Recebido em 17/5/2016 - Aprovado em 13/2/2017}

\section{Referências bibliográficas}

ADACHI, Ana Amélia Chaves Teixeira. Evasão e evadidos nos cursos de graduação da Universidade Federal de Minas Gerais. Dissertação (Mestrado em Educação) Universidade Federal de Minas Gerais, Belo Horizonte, 2009.

AMARAL, Regiane da Silva; NASCIMENTO, Sara Diniz. Diagnóstico situacional da política de assistência estudantil no âmbito do Instituto Federal do Maranhão: estudo de caso nos Campi Buriticupu e Centro Histórico. In: Anais... Congresso de Pesquisa e Inovação da Rede Norte Nordeste de Educação Tecnológica, Maceió: IFAL, 2010. Disponível em: <http://connepi.ifal.edu.br/ocs/index.php/connepi/CONNEPI2010/ paper/view/336 >. Acesso em: 10 jan. 2015.

ANGELIM, Isabel Cristina Sampaio. Política de assistência estudantil na universidade pública: desafios para construção de uma concepção de direito de cidadania. In: Anais... Seminário Políticas Sociais e Cidadania, Salvador: UCSAL, 2010. Disponível em: $<$ http://www.interativadesignba.com.br/III_SPSC/arquivos/sessao7/199.pdf $>$. Acesso em: 10 jan. 2015. 
ANDIFES. 2011. Perfil socioeconômico e cultural dos estudantes de graduação das universidades federais brasileiras. Fórum Nacional de Pró-Reitores de Assuntos Comunitários e Estudantis (FONAPRACE). Brasília, 2011.

ARAÚJO, Josimeire de Omena. O elo assistência e educação: análise assistência/ desempenho no Programa Residência Universitária alagoana. Dissertação (Mestrado em Serviço Social) — Universidade Federal de Pernambuco, Recife, 2003.

ARAÚJO, Fabricia Silva de; BEZERRA, Juliane Cristina Bisco. Tendências da política de assistência ao estudante no contexto da reforma universitária brasileira. In: Anais... Jornada Internacional de Políticas Públicas, São Luís: UFMA, 2007. Disponível em: $<$ http://www.joinpp.ufma.br/jornadas/joinppIII/html/ Trabalhos/EixoTematicoA/ cff899684c7ef149b573Fabr\%C3\%ADcia\%20Silva\%20de\%20Ara\%C3\%BAjo.pdf>. Acesso em: 10 jan. 2015.

BARBOSA, Roseane de Almeida. A assistência ao estudante da residência universitária da UFPB. Dissertação (Mestrado em Serviço Social) - Universidade Federal da Paraíba, João Pessoa, 2009.

BARDAGI, Marucia Patta; HUTZ, Cláudio Simon. "Não havia outra saída": percepções de alunos evadidos sobre o abandono do curso superior. Psico-USF (Impr.), Itatiba, v. 14, n. 1, Abr. 2009. Disponível em: <http://www.scielo.br/scielo.php?script= sci_arttext \&pid=S1413-82712009000100010 \&lng=en\&nrm=iso $>$. Acesso em: 15 dez. 2014.

BRASIL. Decreto n. 7.234, de 19 de julho de 2010. Dispõe sobre o Programa Nacional de Assistência Estudantil — PNAES. Disponível em: <http://www.planalto.gov.br/ ccivil_03/_Ato2007-2010/2010/Decreto/D7234.htm>. Acesso em: 20 dez. 2014.

. Portaria Normativa n. 39, de 12 de dezembro de 2007. Institui o Programa Nacional de Assistência Estudantil — PNAES. Disponível em: http://portal. mec.gov. br/arquivos/pdf/portaria_pnaes.pdf. Acesso em: 20 dez. 2014.

. Lei n. 10.172, de 9 de janeiro de 2001. Aprova o Plano Nacional de Educação e dá outras providências. Disponível em: <http://www.planalto.gov.br/ ccivil_03/leis/ leis_2001/110172.htm>. Acesso em: $20 \mathrm{dez} .2014$.

. Lei n. 9.394, de 20 de dezembro de 1996. Estabelece as diretrizes e bases da educação nacional. Disponível em: <https://www.planalto.gov.br/ccivil_03/Leis/L9394. htm>. Acesso em: 15 dez. 2014.

. Lei $n$. 8.742, de 7 de dezembro de 1993. Dispõe sobre a organização da Assistência Social e dá outras providências. Disponível em: $<$ http://www.planalto. gov. br/ccivil_03/leis/L8742.htm>. Acesso em: 23 jan. 2015. 
BRASIL. Constituição da República Federativa do Brasil de 1988. Disponível em: $<$ http://www.planalto.gov.br/ccivil_03/constituicao/constituicao.htm>. Acesso em: 8 nov. 2014.

. Decreto n. 69.927, de 13 de janeiro de 1972. Institui em caráter nacional o Programa "Bolsa de Trabalho". Disponível em: < http://www2.camara.leg.br/legin/fed/ decret/1970-1979/decreto-69927-13-janeiro-1972-418292-publicacaooriginal-1-pe. html>. Acesso em: 8 nov. 2014.

Lei n. 5.692, de 11 de agosto de 1971. Fixa Diretrizes e Bases para o ensino de $1^{\circ}$ e $2^{\circ}$ graus, e dá outras providências. Disponível em: <http://www.planalto.gov. br/ccivil_03/leis/15692.htm>. Acesso em: 8 nov. 2014.

. Constituição da República Federativa do Brasil de 1967. Disponível em: $<$ http://www.planalto.gov.br/ccivil_03/constituicao/constituicao67.htm>. Acesso em: 8 nov. 2014.

. Lei n. 4.024, de 20 de dezembro de 1961. Fixa as Diretrizes e Bases da Educação Nacional. Disponível em: <http://www.planalto.gov.br/ccivil_03/leis/14024.htm>. Acesso em: 8 nov. 2014.

. Constituição da República dos Estados Unidos do Brasil de 1946. Disponível em: $<$ http://www.planalto.gov.br/ccivil_03/constituicao/_constituicao46.htm $>$. Acesso em: 8 nov. 2014.

. Constituição da República dos Estados Unidos do Brasil. Disponível em: $<$ http://www.planalto.gov.br/ccivil_03/constituicao/constituicao34.htm>. Acesso em: 8 nov. 2014.

. Decreto n. 19.851, de 11 de abril de 1931. Dispõe que o ensino superior no Brasil obedecerá, de preferência, ao systema universitario, podendo ainda ser ministrado em institutos isolados, e que a organização technica e administrativa das universidades é instituida no presente Decreto, regendo-se os institutos isolados pelos respectivos regulamentos, observados os dispositivos do seguinte Estatuto das Universidades Brasileiras. Disponível em: <http://www2.camara.leg.br/legin/fed/decret/1930-1939/ decreto-19851-11-abril-1931-505837-publicacaooriginal-1-pe.html>. Acesso em: 8 nov. 2014.

BOSCHETTI, Ivanete. A Assistência Social no Brasil: um direito entre originalidade e conservadorismo. 2. ed. Brasília: GESST/SER/UnB, 2003. 
COSTA, Simone Gomes. A equidade na educação superior: uma análise das Políticas de Assistência Estudantil. Dissertação (Mestrado em Sociologia) — Universidade Federal do Rio Grande do Sul, Porto Alegre, 2010.

CURY, Carlos Roberto Jamil. Estado e políticas de financiamento em educação. Educ. Soc., Campinas, v. 28, n. 100, Oct. 2007. Disponível em: <http:/www.scielo. br/scielo. php? script $=$ sci_arttext\&pid $=$ S0101-73302007000300010\&lng $=$ en\&nrm $=$ iso $>$. Acesso em: 20 jan. 2015.

FELICETTI, Vera Lucia; MOROSINI, Marília Costa. Equidade e iniquidade no ensino superior: uma reflexão. Ensaio: aval.pol.públ.Educ., Rio de Janeiro, v. 17, n. 62, mar. 2009. Disponível em: $<$ http://www.scielo.br/scielo.php?script=sci_arttext \&pid=S0104$40362009000100002 \& \operatorname{lng}=\mathrm{en} \& n \mathrm{~nm}=\mathrm{iso}>$. Acesso em: 20 jan. 2015.

FINATTI, Betty Elmer; ALVES, Jolinda de Moraes; SILVEIRA, Ricardo de Jesus. Perfil sócio, econômico e cultural dos estudantes da Universidade Estadual de Londrina-UEL indicadores para implantação de uma política de assistência estudantil. Libertas, Juiz de Fora, v. 6 e 7, n. 1 e 2, p. 246-264, jan.-dez./2006, jan.-dez./2007. Disponível em: <http:// www.ufjf.br/revistalibertas/files/2011/02/artigo_12_7.pdf $>$. Acesso em: 23 jan. 2015.

GARRIDO, Edleusa Nery; MERCURI, Elizabeth Nogueira Gomes da Silva. A moradia estudantil universitária como tema na produção científica nacional. Revista Semestral da Associação Brasileira de Psicologia Escolar e Educacional, v. 17, n. 1, p. 87-95, jan.-jun./2013. Disponível em: <http://www.scielo.br/pdf/pee/v17n1/a09v17n1.pdf> Acesso em: 21 jan. 2015.

MENEZES, Josilene Estácio. A politica de assistência ao estudante: a bolsa de trabalho como instrumento de direito para a formação do aluno no CEFET-AL. Dissertação (Mestrado em Serviço Social) — Universidade Federal de Pernambuco, Recife, 2003.

OSSE, Cleuser Maria Campos; COSTA, Ileno Izídio da. Saúde mental e qualidade de vida na moradia estudantil da Universidade de Brasília. Estud. psicol. (Campinas), Campinas, v. 28, n. 1, mar. 2011. Disponível em: $<$ http://www.scielo.br/scielo. php?script=sci arttext\&pid=S0103-166X2011000100012\&lng=en\&nrm=iso>. Acesso em: 20 jan. 2015.

RAMALHO, Ludmila Eleonora Gomes. Abordagem avaliativa da política de assistência estudantil em uma instituição de ensino profissional. Dissertação (Mestrado Profissional em Gestão e Avaliação da Educação Pública) - Universidade Federal de Juiz de Fora, Juiz de Fora, 2013. 
RAMOS, Lila de Fátima de Carvalho. A assistência ao estudante nas IFES em contexto brasileiro: o Programa Saudavelmente da Procom-UFG. Dissertação (Mestrado em Serviço Social) — Pontifícia Universidade Católica de Goiás, Goiânia, 2012.

SOUSA, Livia Mesquita de. Significados e sentidos das casas estudantis: um estudo com jovens universitários. Dissertação (Mestrado em Psicologia) — Universidade Católica de Goiás, Goiânia, 2005.

VARGAS, Michely de Lima Ferreira. Ensino superior, assistência estudantil e mercado de trabalho: um estudo com egressos da UFMG. Dissertação (Mestrado em Educação) — Universidade Federal de Minas Gerais, Belo Horizonte, 2008.

VASCONCELOS, Natália. Programa Nacional de Assistência Estudantil: uma análise da assistência estudantil ao longo da história da educação superior no Brasil. Revista da Católica, Uberlândia, v. 2, n. 3, p. 399-411, 2010. Disponível em: <http://www. catolicaonline.com.br/revistadacatolica/artigosv2n3/29-Pos-Graduacao.pdf $>$ Acesso em: 15 jan. 2015. 